\title{
A COURSE IN \\ PURE AND APPLIED MATHEMATICS
}




\title{
A COURSE IN \\ PURE AND APPLIED MATHEMATICS
}

\author{
BY \\ H. J. HALSTEAD B.A., Dip. Ed. (Melb) \\ HEAD, MATHEMATICS DEPARTMENT, \\ ROYAL MELBOURNE INSTITUTE OF TECHNOLOGY \\ AND \\ D. A. HARRIS B.A., B.Ed. (Melb) \\ SENIOR LECTURER, MATHEMATICS DEPARTMENT \\ ROYAL MELBOURNE INSTITUTE OF TECHNOLOGY
}

Macmillan Education

I 963 


\title{
ISBN 978-1-349-81606-4 ISBN 978-1-349-81604-o (eBook)
}

DOI 10.1007/978-1-349-81604-0

\author{
Copyright (C) H. J. Halstead and D. A. Harris 1963
}

Softcover reprint of the hardcover 1st edition 1963 978-0-333-09956-8

MACMILLAN AND COMPANY LIMITED

St Martin's Street London WC2

also Bombay Calcutta Madras Melbourne

THE MACMILLAN COMPANY OF CANADA LIMITED

Toronto

ST MARTIN'S PRESS INC

New York 


\section{PREFACE}

IT is customary in the preface to a text book to write about the scope of the book, to express some general ideas of the authors relevant to the subject matter and to express their thanks. We will not break with tradition here, although we hope in the text which follows that we have not let ourselves be so bound.

The book is intended for students who have already taken a first course of calculus and revision material appropriate to such a course is included. We have attempted to present material logically but we have not aimed at being rigorous, so that, for example, proofs requiring the notion of continuity are not included. We have not followed the path of those interested only in applications of mathematics nor of those who are interested only in that part of mathematics which gives it a claim to be ranked among the arts and humanities. We believe that history points to the best being found in a blending of both aspects so that understanding and the acquisition of results go hand in hand.

The setting up of appropriate algebraic and differential equations has been assumed the central part of applied mathematics and a number of exercises have been included which have this as the end point. The introduction of literal data and the use of general methods rather than special procedures have been considered important.

The book could provide a two year course, the first of which could be sections $1 \cdot 1-1 \cdot 52,2 \cdot 1-2 \cdot 7,3 \cdot 1-3 \cdot 7,4 \cdot 1-4 \cdot 64,5 \cdot 1-5 \cdot 3,6 \cdot 1-6 \cdot 32,8 \cdot 1-8 \cdot 54$, $9 \cdot 1-9 \cdot 5,10 \cdot 1-10 \cdot 5,12 \cdot 1-12 \cdot 4$ and $13 \cdot 1$. Set 1 of the General Miscellaneous Exercises is limited to these sections.

We thank Dr H. Laszlo formerly of R.M.I.T., now of Monash University, for many valuable discussions and ideas, Dr K. M. Bing of R.M.I.T. for reading the manuscript and making many suggestions for its improvement, the staff of the Mathematics Department of R.M.I.T. for their cooperation in checking many answers, $\mathrm{Mr} \mathrm{J}$. C. Vickery for his painstaking care in drawing the diagrams and the Education Department of Victoria for permission to use questions from their examination papers.

H. J. H.

D. A. H. 


\section{CONTENTS}

CHAPTER

1. Co-ordinate Systems

PAGE

$1 \cdot 1$ Introduction

1.2 Rectangular Cartesian Co-ordinates

1.3 Polar Co-ordinates

1.4 Transformation, Cartesian and Polar Co-ordinates

1.5 Rectangular Cartesian Co-ordinates in Three Dimensions

1.6 Cylindrical Co-ordinates

1.7 Spherical Co-ordinates

2. SERIES

$2 \cdot 1$ Sequences

2.2 Series-Arithmetic Forms

2.3 Series-Algebraic Forms

2.4 The Formation of Power Series

2.5 Operations on Power Series

2.6 Application of Power Series

2.7 The Ratio Test of Convergence

2.8 Taylor's Series

3. Complex Numbers and Elementary Functions

3.1 The Real-Imaginary Form of a Complex Number

3.2 The Modulus-Phase Form of a Complex Number

3.3 Exponential and Circular Functions

3.4 Hyperbolic Functions

3.5 The Logarithm Function

3.6 Inverse Circular Functions

3.7 Inverse Hyperbolic Functions

3.8 Mapping $w=f(z)$

4. Differentiation

4.1 Basic Facts

4.2 Harder Differentiation

4.3 Applications of Differentiation

4.4 Partial Derivatives

4.5 Total Increment Theorem 
4.6 Applications of the Total Increment Theorem

4.7 Higher Order Partial Derivatives

4.8 Maxima and Minima Problems

4.9 The Method of Least Squares

5. INTEGRATION

5.1 Summary, Including some Standard Forms

5.2 Standard Procedures

5.3 Applications of Definite Integrals

5.4 Double Integrals

5.5 Higher Order Multiple Integrals

6. Differential Equations

6.1 Formation of Differential Equations

6.2 First Order Differential Equations

6.3 Second Order Differential Equations

6.4 Higher Order Linear Differential Equations

6.5 Operator $D$

6.6 Simultaneous Linear Differential Equations

7. FoURIER SERIES

$7 \cdot 1$ Introduction

7.2 Successive Approximations to a Function of Period $2 \pi$

7.3 A Short Cut to the Formulae for the Fourier Coefficients

$7 \cdot 4$ Special Cases

7.5 Representation of a Function over a Given Interval

7.6 Numerical Harmonic Analysis

8. VeCtORS

8.1 Fundamental Notions

8.2 Magnitude or Module and Orientation of a Vector

8.3 Cartesian Component Form of a Vector

8.4 Products of Vectors

8.5 Differentiation of a Vector with respect to a Scalar

8.6 Application of Vectors to Geometry

8.7 Components of Linear Velocity and Acceleration

8.8 Triple Products 
9.1 Fundamental Ideas

9.2 Linear Motion

9.3 Momentum and Impulse

9.4 Kinetic Energy, Work, Power

9.5 Plane Motion of a Particle

10. Rotation of a Lamina about a Fixed Axis

10.1 Rigid Body

10.2 Angular Momentum Principle

10.3 The Equation $I_{O} \ddot{\theta}=L_{O}$ for Rotation of a Lamina about a Fixed Axis Perpendicular to its Plane

10.4 Kinetic Energy, Work done by Torque, Power of Torque

10.5 Impulse of Torque, Moment of Impulse

10.6 Reaction at a Pivot

11. General Motion of a Rigid Lamina in a Plane

$11 \cdot 1$ Kinematics

11.2 Angular Momentum Principle

11.3 The Equation $I_{G} \ddot{\theta}=L_{G}$

11.4 Kinetic Energy, Work

11.5 Impulse of Torque

12. Simple R.L.C. Circuits

12.1 Notation and Kirchhoff's Laws

12.2 Resistance

12.3 Capacitance

$12 \cdot 4$ Inductance

13. Oscillations

13.1 Simple Harmonic Oscillations

13.2 Free Damped Oscillations

13.3 Forced Oscillations (without damping)

13.4 Forced Oscillations (with damping)

14. Statics of Simple Continuous Systems

14.1 Rigid Bars

14.2 Perfectly Flexible Inextensible Strings in Contact with Surfaces

14.3 Flexible Inextensible Strings hanging under Gravity 
14.4 Properties of the Common Catenary

14.5 Perfectly Flexible Elastic Strings

15. Small Deflection of Beams

$15 \cdot 1$ Introduction

15.2 Transverse Loads

15.3 The General Case of Small Deflections of a Naturally Straight Beam

General Miscellaneous Exercises. Set 1

General Miscellaneous Exercises. Set 2

APPENDIX A. INTEGRALS 